\title{
A rare cause of stridor: Isolated tracheal amyloidosis
}

\author{
Numbere K Numbere MBBS MRCP BSc ${ }^{1}$, Jamal Grayez MBBS ${ }^{2}$
}

\begin{abstract}
NK Numbere, J Grayez. A rare cause of stridor: Isolated tracheal amyloidosis. Can Respir J 2014;21(5):273-275.

A 50-year-old man presented to clinic with a two-year history of progressive exertional dyspnea and voice hoarseness. This history suggested upper airways obstruction, which was confirmed on computed tomography imaging that revealed extensive thickening of the proximal tracheal wall causing severe luminal narrowing. Bronchoscopic debulking was then performed and the samples obtained confirmed tracheal amyloidoisis. Extensive investigation confirmed that disease was localized solely to the trachea. Ultimately, after multiple discussions, the chosen treatment modality was radiotherapy, which proceeded relatively uneventfully and achieved excellent radiological and clinical response. Although tracheal amyloidosis is rare, it is most commonly observed as part of a multisystem presentation. The present report describes the even more uncommon diagnosis of isolated tracheal amyloidosis and highlights the role of radiotherapy in its management.
\end{abstract}

Key Words: Tracheal amyloid; Tracheal radiotherapy; Stridor

Learning objectives

- To be aware that amyloidosis can occur as an isolated tracheal disease.

- To recognize the roles of interventional bronchoscopy and radiotherapy in the management of tracheal amyloidosis.

CanMeds Competency: Medical Expert Collaborator

Pretest

- What management options can be considered for tracheal amyloidosis?

\section{CASE PRESENTATION}

A 50-year-old man presented to the respiratory clinic with a two-year history of vocal hoarseness and slowly progressive exertional dyspnea. He was able to work and run, but also reported four months of 'noisy' breathing, particularly on exertion. He was otherwise fit, an ex-smoker of 20 pack-years, with no relevant medical or family history.

Examination was essentially unremarkable aside from one key finding. Despite no signs of respiratory distress, there was an audible, quiet inspiratory stridor. As a result, the provisional diagnosis was obstruction of a large airway. This was confirmed on a computed tomography (CT) scan that revealed circumferential thickening of the proximal trachea starting at the level of the cricoid and continuing for a length of $22 \mathrm{~mm}$ while reducing the lumen to a transverse diameter of $5.5 \mathrm{~mm}$ at its narrowest point (Figure 1). There was no evidence of extrinsic compression, with no mediastinal masses or any significant mediastinal lymphadenopathy.

Given the narrow calibre of the trachea and the risk of causing significant life-threatening bleeding and/or debris with an invasive procedure, he proceeded to rigid bronchoscopy rather than awake flexible bronchoscopy, thus enabling better visibility, suction capability and hemostatic options. Bronchoscopy revealed that the extent of

\author{
Une rare cause de stridor : l'amylose trachéale \\ isolée
}

Un homme de 50 ans s'est rendu à la clinique parce que, depuis deux ans, il faisait de la dyspnée à l'effort allant en s'aggravant et que sa voix devenait rauque. Ses antécédents laissaient supposer une obstruction des voies aériennes supérieures, confirmée par une tomodensitométrie qui a révélé un important épaississement de la paroi proximale de la trachée, responsable d'un rétrécissement marqué de la lumière. Une réduction bronchoscopique a confirmé l'amylose trachéale. Des examens approfondis ont également confirmé une atteinte limitée à la trachée. Après de multiples discussions, la radiothérapie a été retenue comme modalité de traitement, laquelle s'est déroulée relativement sans incident et a suscité une excellente réponse radiologique et clinique. L'amylose trachéale est rare, mais on l'observe surtout en présentation multisystémique. Le présent rapport décrit le diagnostic encore plus rare d'amylose trachéale isolée et souligne le rôle de la radiothérapie pour la prise en charge.

disease was greater than appreciated on CT, with more profound subglottic disease. A diffuse yellow granular and vascular infiltrating mass was observed extending from the level of the vocal cords spreading circumferentially around and distally along the trachea involving all of its rings. The deposits were confluent in the upper one-third and middle portions of the trachea. Flexible bronchoscopy through the rigid bronchoscope revealed no evidence of bronchial involvement. Multiple biopsies were taken and histological examination of these using hemotoxylin and eosin staining revealed an amorphous, eosinophilic material. Congo red staining demonstrated the characteristic orange-red appearance of amyloid deposits (Figure 2). Further confirmation was provided by apple-green birefringence under polarized light, a classic feature of amyloid. There was no positive signal on application of immunofluorescent stains and it was, thus, typed as nonAA amyloid.

Before a definitive management plan could be agreed on and implemented, he presented to hospital two weeks later with progressively worsening dyspnea such that he was now breathless at rest. The stridor was now louder and biphasic in character. Althought there was no history to suggest intercurrent infection or bleeding, broad-spectrum antibiotics and empirical steroids were commenced. Compared with his initial scan, his repeat CT scan showed interval progression in his subglottic and upper tracheal disease over a period of one month. Given the extent of his disease, he proceeded to a combined laryngoscopy and rigid bronchoscopy under general anesthesia performed as a joint procedure by otolaryngologists and thoracic surgeons. A nasal endoscopy performed before the procedure confirmed that laryngeal microdebridement would, in fact, be appropriate in this instance. An Efer Dumon (Efer Broncho, France) bronchoscope was inserted through the cords and the patient was jet ventilated through the bronchoscope for the first part of the operation. Interestingly, there had been no change in the diminution of his tracheal lumen compared with his previous bronchoscopy but there was, as before, significant subglottic involvement. There was no bleeding observed in the airway

${ }^{1}$ Department of Respiratory Medicine, Churchill Hospital, Oxford; ${ }^{2}$ Horton Hospital, Banbury, England, United Kingdom

Correspondence: Dr Numbere K Numbere, Department of Respiratory Medicine, Churchill Hospital, Old Road, Headington, Oxford,

England OX3 7LE, United Kingdom. Telephone 44-776-049-6152, e-mail numbere@doctors.org.uk 


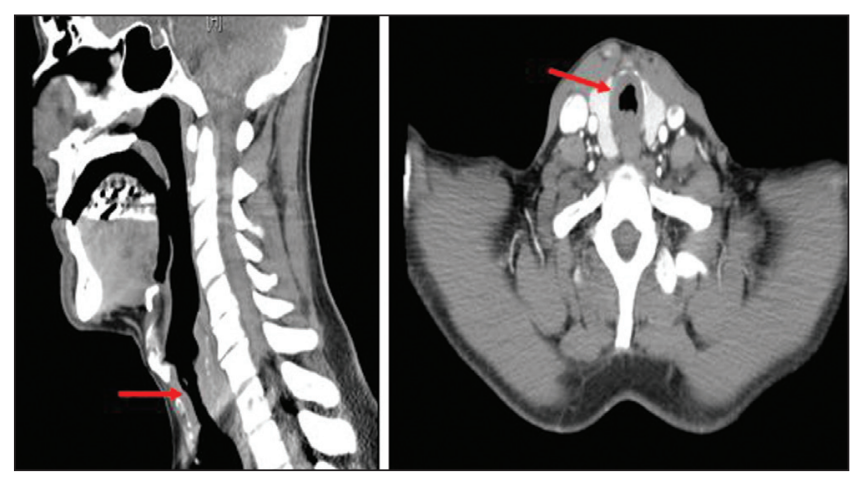

Figure 1) Tracheal intraluminal thickening secondary to amyloid deposition in sagittal and transverse cross section (arrows)

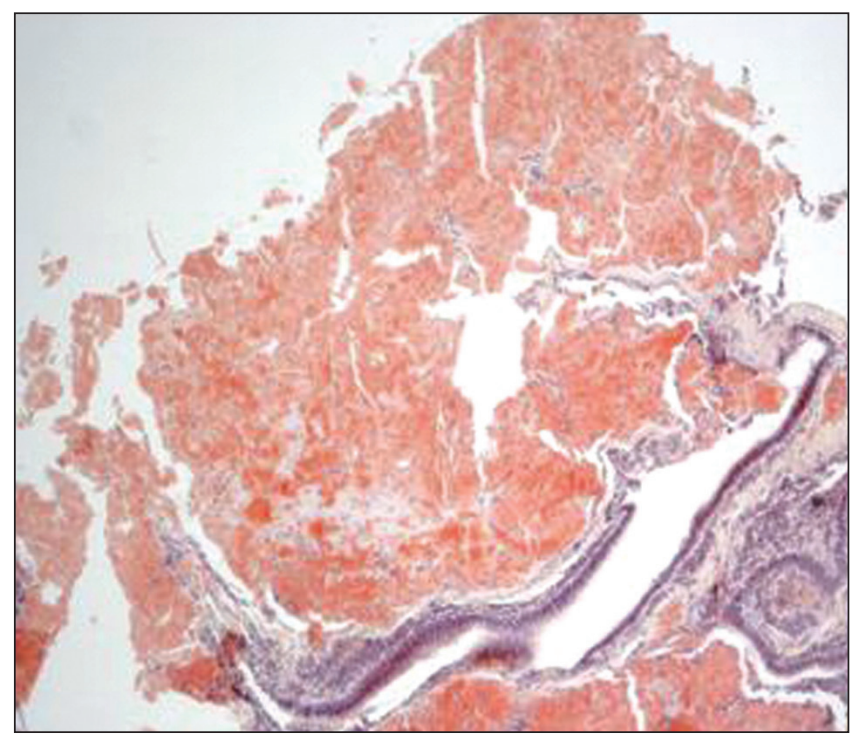

Figure 2) Congo red-stained amyloid tissue in tracheal biopsy. Original magnification $\times 40$

on inspection. Extensive mechanical debulking was performed in the middle trachea, where disease involvement had caused significant luminal narrowing. Hemostasis was achieved using argon plasma coagulation where necessary. The bronchoscope was replaced with a suspension laryngoscope through which the patient continued to be jet ventilated. A Diego microdebrider (Olympus, Japan) was introduced via the laryngoscope, which was successfully used to restore luminal patency at a subglottic level. By the end of the procedure, an essentially normal-calibre lumen was restored - this is demonstrated radiologically in Figure 3. Stenting was not performed because any stent would have had to be very high and close to the cords given his disease extent. This could create speech problems and could also lead to granuloma formation, a potential cause of stenosis above a stent. Another reason not to stent was that there was, and still is, uncertainty about the natural history of the disease, particularly in a relatively young man.

He was subsequently referred to the National Amyloidosis Centre in Royal Free Hospital (London, United Kingdom), where a battery of investigations were performed and confirmed that this was, in fact, isolated spontaneous localized amyloidosis. These included a normal immunoglobulin screen, a negative myeloma screen, a normal echocardiogram and normal serum amyloid P scintigraphy with no visceral uptake.

After extensive discussions regarding long-term management approaches including recurrent debulking with risk of stricture formation, tracheostomy and stenting, it was decided to proceed with

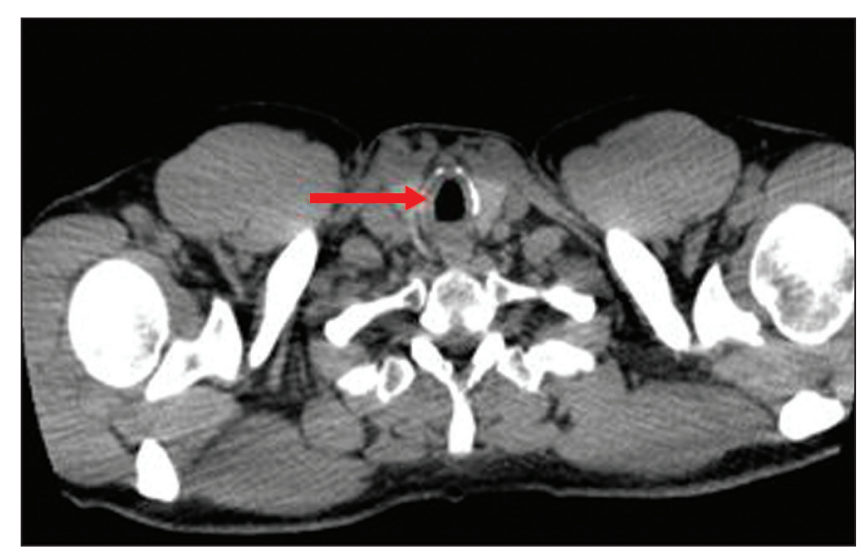

Figure 3) Marked reduction in tracheal intraluminal thickening following bronchoscopic debulking (arrow)

radiotherapy, 20 Gy in 10 fractions. The patient completed the course and the only side effect was mild odynophagia due to esophagitis. He reported further improvement in voice and fitness postradiotherapy.

An interval scan 12 months after completion of radiotherapy showed no disease progression and the patient remained asymptomatic, with normal spirometry and flow-volume loops 14 months after radiotherapy.

\section{DISCUSSION}

Amyloidosis is a disease characterized by the deposition of fibrillary protein amyloid in the extravascular spaces causing insidious, progressive damage to tissues and organs. The term 'amyloid' is derived from the Latin 'amylum', referring to starch and was first used to describe this substance by German doctor and pathologist Rudolf Virchow. Amyloid had been encountered previously, but Virchow noted an interaction between iodine and cerebral tissue samples from patients with cerebral amyloidosis and named it on the assumption that it was structurally related to starch (1).

The diagnosis is based on the isolation and identification of amyloid protein in tissue biopsied from an affected organ and appropriate staining (eg, Congo red). There are $>20$ types of amyloid protein identified that can cause a wide variety of clinical presentations, broadly divided into systemic and localized amyloidosis (2).

Pulmonary involvement in systemic amyloidosis occurs mainly with systemic amyloid light-chain disease and is usually asymptomatic. Smith et al (3) reported that $88 \%$ of patients with systemic amyloid disease had pulmonary involvement postmortem. Utz et al (4) found 35 of 55 pulmonary amyloid patients had systemic disease. There are four main patterns of isolated amyloid of the respiratory tract: infiltrative parenchymal amyloidosis, rare because it is usually associated with systemic amyloidosis; nodular parenchymal amyloid, which rarely requires treatment; tracheobronchial amyloid, which can be diffuse or nodular (5); and finally, pseudotumour tracheobronchial amyloid, which has the appearance of a discrete tumour (6). In 1983, Thompson and Citron (7) identified 126 cases of localized primary pulmonary amyloid, 57 of which had tracheobronchial disease, 55 had nodular parenchymal disease, 10 had pseudotumour disease and four had diffuse parenchymal involvement (7). More recently, a case series involving patients with amyloid with isolated respiratory system involvement demonstrated that of 11 patients with isolated primary pulmonary disease, seven had tracheobronchial amyloid, three had nodular parenchymal disease and one had diffuse parenchymal disease (8).

Fewer than 200 cases of primary isolated tracheobronchial amyloid have been identified, and isolated diffuse infiltrative tracheal amyloidosis is even more rare (9-12). It is, as demonstrated in the present case, of great importance to exclude involvement of other systems to determine prognosis and plan management. The bronchoscopic appearance can vary from diffuse confluent disease in the present case to nodular 
deposition; presenting symptoms vary including cough, hemoptysis and, in extreme cases such as this, stridor $(2,3)$. The vast majority of cases are histologically amyloid light-chain type (13).

The present patient experienced a gradual deterioration after bronchoscopy, which is unusual for airway edema postbronchoscopy; intravenous dexamethasone was administered before the procedure. His decline was likely unrelated to his bronchoscopy, especially in the context of radiological evidence of progressive disease. Because this patient ultimately presented after diagnosis as an emergency, his initial management was surgical: bronchoscopic laser photocoagulation and manual debulking. Beyond repeated bronchoscopic intervention, more radical long-term surgical options include stenting with simple stents or Y stents depending on disease extent; tracheostomy formation to bypass diseased trachea in cases of rapidly progressive infiltrative amyloid; and finally, resection of short tracheal segments in localized pseudotumour disease (14). Stem cell tracheal transplantation is an area of some excitement because it may provide an additional treatment option in the future (15). Surgical options are, however, always limited by risk of bleeding given the friable nature of amyloid as well as a potential need for recurrent procedures with a theoretical risk of ultimately leading to stricture formation (16). It is for this reason that radiotherapy was used as a consolidation treatment with the aims of not only causing disease regression and symptomatic relief but also of reducing the need for recurrent invasive surgery.

The body of evidence supporting radiotherapy is limited and includes a handful of case reports and one case series (17-20). A 2007 case series investigated seven patients, all given 20 Gy in 10 fractions, with a follow-up period ranging from 10 to 69 months (20). All patients had favourable responses, with five reporting improvement in their symptoms and two reporting no symptom progression during the follow-up period. The authors go as far as recommending radiotherapy as the primary treatment modality in cases of symptomatic bulky disease where bronchoscopic recanalization is not possible. This was based on the premise that although there are potential risks, such as radiation pericarditis, esophagitis and pneumonitis, their data

\section{REFERENCES}

1. Virchow VR. Ueber einem Gehirn und Rueckenmark des Menschen aufgefundene Substanz mit chemischen reaction der Cellulose. Virchows Arch Pathol Anat 1854;6:1358.

2. Buxbaum JN. The systemic amyloidoses. Curr Opin Rheumatol 2004;16:67-75.

3. Smith RR, Hutchins GM, Moore GW, Humphrey RL. Type and distribution of pulmonary parenchymal and vascular amyloid. Correlation with cardiac amyloidosis. Am J Med 1979;66:96-104.

4. Utz JP, Swensen SJ, Gertz MA. Pulmonary amyloidosis:

The Mayo Clinic experience from 1980 to 1993. Ann Intern Med 1996;124:407-13

5. Pitz MW, Gibson IW, Johnston JB. Isolated pulmonary amyloidosis: Case report and review of the literature. Am J Hematol 2006;81:212-3.

6. Piazza C, Cavaliere S, Foccoli P, Toninelli C, Bolzoni A, Peretti G. Endoscopic management of laryngotracheobronchial amyloidosis: A series of 32 patients. Eur Arch Otorhinolaryngol 2003;260:349-54.

7. Thompson PJ, Citron KM. Amyloid and the lower respiratory tract. Thorax 1983;38:84-7.

8. Chu H, Zhao L, Zhang Z, Gui T, Yi X, Sun X. Clinical characteristics of amyloidosis with isolated respiratory system involvement: A review of 13 cases. Ann Thorac Med 2012;7:243-9.

9. Deodhare SG, Dasgupta G. Primary amyloidosis of the trachea. J Laryngol Otol 1975;89:645-51.

10. Sharma D, Katlic MR. Localised tracheal amyloidosis. J Bronchology Interv Pulmonol 2006;13:19-20.

11. Alekseev VG, Sinopal'nikov AI, et al. Isolated amyloidosis of the trachea. Ter Arkh 1986;58:133-5. suggested radiotherapy may, in fact, change the disease course because there was no symptom recurrence through a relatively long follow-up period. Interestingly, they also noted that forced expiratory volume in $1 \mathrm{~s}$ and flow-volume loops did not correlate well with symptomatic improvement. There may also be a role for radiotherapy in primary pulmonary nodular amyloidosis, as detailed in a recent case report (21).

The literature on isolated tracheobronchial amyloid is, on the whole, sparse, particularly in terms of follow-up data; consequently, there are no concrete prognostic data. Survival has been linked to degree of respiratory impairment and extent of disease, with more proximal disease being a poor prognostic marker (22).

The present case illustrates that amyloidosis can present as isolated tracheal disease causing symptomatic tracheal narrowing. We have also reported that radiotherapy is a viable noninvasive treatment modality that should be considered and implemented early in symptomatic cases.

Post-test
- What management options can be considered for tracheal
amyloidosis?
Management options for symptomatic isolated tracheal amyl-
oidosis include repeated bronchoscopic debulking or laser photoco-
agulation, stenting, radiotherapy, segmental tracheal resection,
tracheostomy formation or, potentially, tracheal transplantation.
Radiotherapy is a relatively accessible treatment modality that,
unlike other options, may change the disease course and has an
acceptable side-effect profile. Thus, its use should be considered in
the management of this disease and, consequently, cases should be
discussed in a multidisciplinary setting with respiratory physicians,
thoracic surgeons, radiologists and clinical oncologists.

DISCLOSURES: The authors have no financial disclosures or conflicts of interest to declare.

12. Jurčevski I, Vrčić A, et al. Localised tracheal amyloidosis. Acta Clin Croat 2005;44:303-8.

13. Gillmore JD, Hawkins PN. Amyloidosis and the respiratory tract. Thorax 1999;54:444-51.

14. Lang EE, Phelan E, Rowley H. Tracheal amyloidosis - an unusual cause of stridor. Ear Nose Throat J 2009;88:E27.

15. Delaere PR. Tracheal transplantation. Curr Opin Pulm Med 2012;18:313-20.

16. Alloubi I, Thumerel M, Bégueret H, Baste JM, Velly JF, Jougon J. Outcomes after bronchoscopic procedures for primary tracheobronchial amyloidosis: Retrospective study of 6 cases. Pulm Med 2012;2012:352719.

17. Monroe AT, Walia R, Zlotecki RA, Jantz MA. A case report of successful treatment with external beam radiation therapy. Chest 2004;125:784-9.

18. Kurrus JA, Hayes JK, Hoidal JR, Menendez MM, Elstad MR. Radiation therapy for tracheobronchial amyloidosis. Chest 1998;114:1189-92.

19. Kalra S, Utz JP, Edell ES, Foote RL. External beam radiation therapy in the treatment of diffuse tracheobronchial amyloidosis. Mayo Clin Proc 2001;76:853-6.

20. Neben-Wittich MA, Foote RL, Kalra S. External beam radiation therapy for tracheobronchial amyloidosis. Chest 2007;132:262-7.

21. Ren S, Ren G. External beam radiation therapy is safe and effective in treating primary pulmonary amyloidosis. Respir Med 2012;106:1063-9.

22. Berk JL, O'Regan A, Skinner M. Pulmonary and tracheobronchial amyloidosis. Seminar Respir Crit Care Med 2002;23:155-65. 


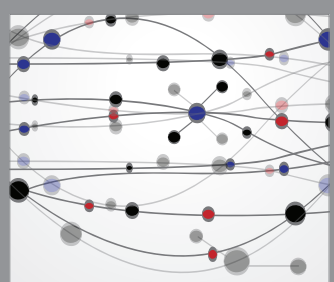

The Scientific World Journal
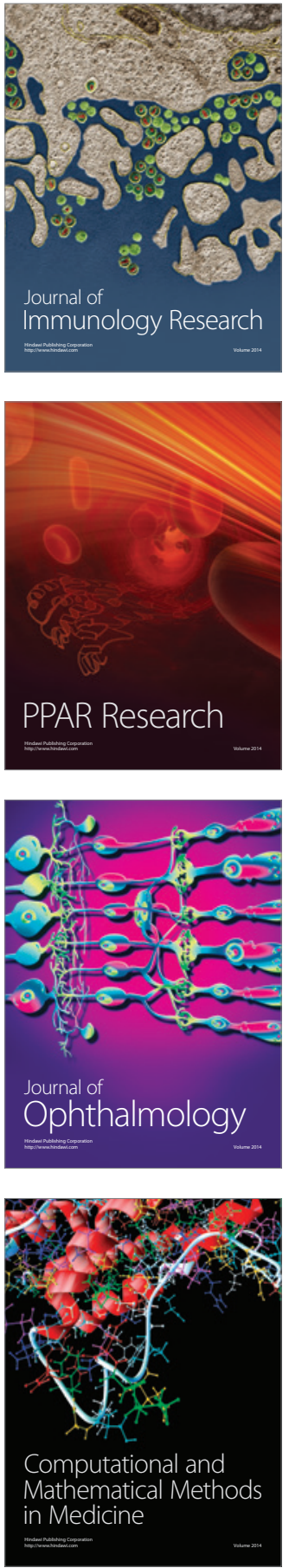

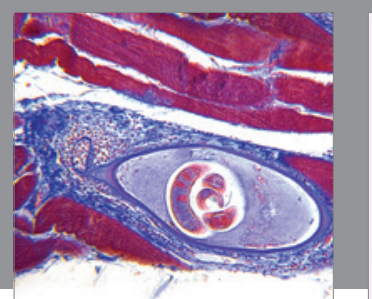

Gastroenterology Research and Practice

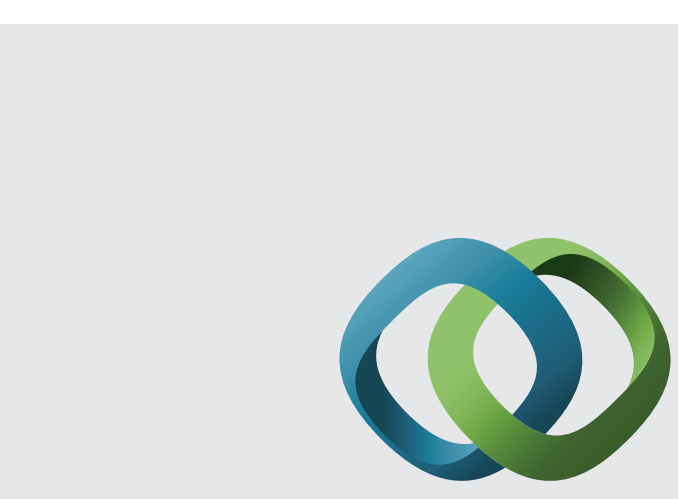

\section{Hindawi}

Submit your manuscripts at

http://www.hindawi.com
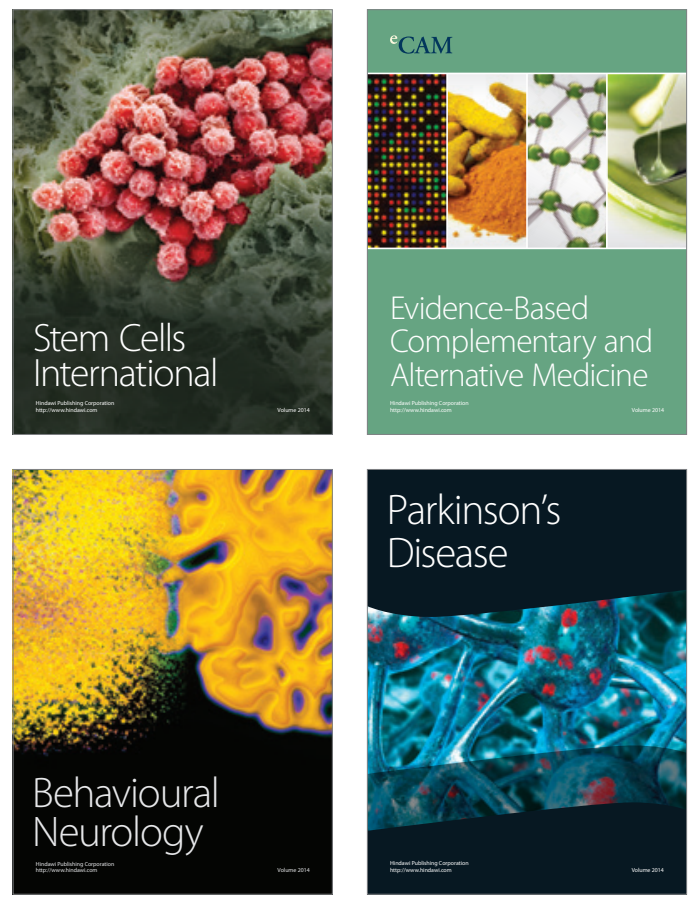
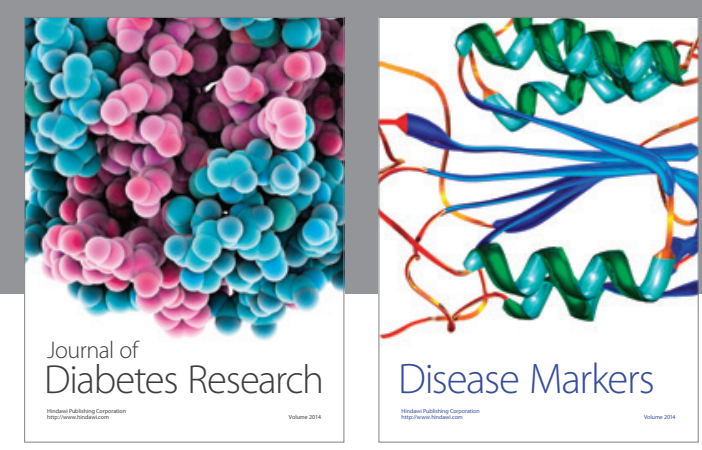

Disease Markers
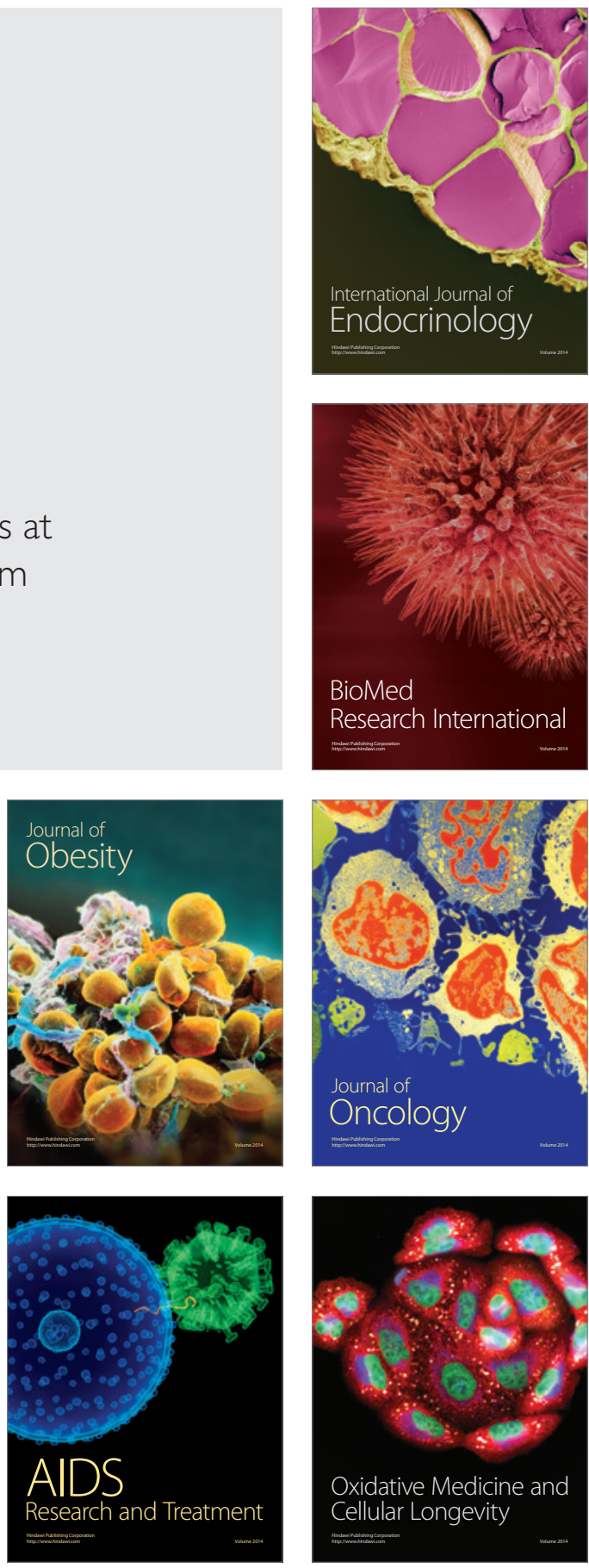